\title{
Production and Characterization of Nanoparticles Lipid Carrier (NLCs) Loaded with Red Clover Isoflavones Extract and Their effect on Serum Lipid profile in Postmenopausal Period
}

\author{
Athraa H. Ali \\ Muna T. Al-Musawi \\ Zainab J Shanan \\ Department of Biotechnology / College of Science / University of Baghdad / Baghdad - Iraq \\ Department of Biology /College of Science for Women /University of Baghdad / Baghdad - Iraq \\ Department of Physics / College of Science for Women / University of Baghdad / Baghdad - Iraq \\ Corresponding author: athraahussain2002@gmail.com \\ Received: 10 /Aug. / 2021, Accepted: 17 /Oct. /2021
}

\begin{abstract}
Plant-derived edible nanoparticles (PDNPs) are nano-sized membrane vesicles released by edible plants. They are non-toxic, have tissue-specific targeting properties, and can be mass-produced , to assess the effect of phytoestrogens (PEs) for treating hyperlipidemia that associated with menopause period using nanoparticles lipid carrier (NLCs) loaded with red clover isoflavones extract (RCIE) compared with hormone replacement therapy (HRT). Study was conducted using fifty adult female mice model for menopause using 4-Vinylcyclohexene dioxide (VCD) and handled as follows for 6 weeks. Two experiments were preformed, the first experiment included 20 mice divided into two groups Group A: Control group has injected $0.1 \mathrm{ml} \mathrm{D.W}$. intraperitoneal (IP) daily. Group B: This group has injected IP daily $160 \mathrm{mg} / \mathrm{kg}$ B.W of VCD. The second experiment was included 30 mice have injected IP daily 160 $\mathrm{mg} / \mathrm{kg}$ of VCD and divided into three groups (C, D and E), (10 / group) then treated with dermal sticker for six weeks: Group C: treated with dermal sticker saturated with $10 \mathrm{ug} / \mathrm{kg} \mathrm{B.W}$ of estradiol benzoate (EB) diluted with virgin coconut oil (VCNO). Group D: treated with dermal sticker saturated with 0.1 of VCNO. Group E: treated with dermal sticker saturated with $0.1 \mathrm{ml}$ of RCIE-NLCs. The results of statistical analysis showed a significant increase in the level of TC, TG, LDL, and VLDL in group VCD. While RCIE-NLCs had a clear effect and significant decreased in the TG, TC, LDL and VLDL cholesterol compared to groups VCD and EB, and significant increase in the HDL-C in group RCIE-NLCs compared to groups VCD and EB. The results of this study revealed that administration of RCIE-NLCs shows an effective to regulation of lipids metabolism disorders due to hormonal changes that associated with menopausal transition via impact of VCD.
\end{abstract}

Keywords: Red clover, Trifolium pratense, Menopause, NLCs, Hyperlipidemia, Estrogen benzoate.

\section{Introduction}

Menopause is clinically recognized when a woman has not menstruated for a year owing to ovarian follicular activity reduction, which generally occurs between the ages of 45 and 55. (1). Due to hormonal changes, such as low production of estrogens and elevated levels of circulating androgens, different lipid metabolic disorders emerge during the menopausal transitional phase, which may lead to the formation of metabolic syndromes, such as type 2 diabetes and cardiovascular disease.( 2). The creation of excess fatty acids, adipocytocines, reactive oxygen species and pro-flammatory cytokines that induce lipid peroxidation and lead to insulin resistance, abdominal adiposity and dyslipidemia is a fundamental element of lipid metabolism and excessive adipose tissue. (3). In the present study, treatment of female mice with VCD to stimulate perimenopause complicated with hyperlipidemia served as the model of perimenopause. Hormone replacement therapy (HRT) was effectively utilized to treat symptoms of menopause for several decades. Long-term HRT consumption nevertheless related with a higher risk of ovarian and endometrial hyperplasia. In connection to cardiovascular and breast cancer.(4) This is why researchers started investigating alternatives to HRT, such phytoestrogenics (PEs). The isoflavonoids are classified into coumestans and isoflavones. (5) Isoflavones can be discovered as traditional medicines to cure many conditions in Red Clover (Trifolium pratense), the native species in the Central Asian region, Europe and North Africa. (6). RC is likely to have beneficial benefits not just on symptoms of menopause, but also on the skeletal system, as well as cardiovascular and hypolipidemic impacts (7). RC has a positive impact on perimenopausal and postmenopausal 
women's lipid profiles. (8) Therefore, is an alternative to traditional hormone treatment derived from several food supplements accessible in markets. $(9,10)$ RC is structurally similar to estrogen compounds but is nonsteroidal, and is believed to have the ability to bind to two subtypes, the selective estrogen receptor (ER), and therefore does not pose a risk to the breast and endometrium. (11). Also, do not increase postmenopausal women's incidence of clotting, making PEs a good option to HRT $(12,13)$ Nanoparticles (NPs), with diameters of $1-100 \mathrm{~nm}$, are described as particles. Nanoparticles Lipid carriers (NLCs) are colloidal with increased stability and efficiency in drug loading of the

\section{Materials and Methods}

Newly dried RC was purchased from local markets of Dohuk province, Iraq. Then, RC was classified by the University of Baghdad grassland, 4-vinylcyclohexene diepoxide (VCD), standards of genistein, glycitein and Malonate, Tween 80 (Sigma Aldrich, Germany. newest generation. The lipids employed for NLC production typically are physiological lipids (biodegradable and biocompatible) to enable medicines to be administered with a decreased, chronic and acute toxicity to the appropriate place of action. (14). NLCs enable the treatment of deep skin layers or even blood circulation to be targeted to make them a high-tech, state-of-the-art technology. A broad range of drug supply methods is referred to by NLCs. The most typical lipid vesicles are known to carry lipophilic or hydrophilic active substances. (15) However, to date, lack or no studies using red clover isoflavones extract (RCIE) as NLCs have reported effects on menopausal status.

\section{Preparation of Red clover isoflavones extract (RCIE)}

The figure 1 shows preparation of RCIE $100 \mathrm{~g}$ of RC was crushed to fine powder by Grinding (Braun $\mathrm{GmbH}$ ). Grinded RC powder was separated to be fine to pass through sieve size $(75-100) \mu \mathrm{m}$. Then added to $500 \mathrm{ml}$ methanol (80\%) and mixed with Magnetic stirrer for 2 hrs. at room temperature. This procedure was repeated two times. The extract was filtered through no.1 filter paper (Whitman International Ltd., Kent, UK) using a Buchner funnel, then the filtrate was concentrated with a rotary evaporator under reduced pressure.

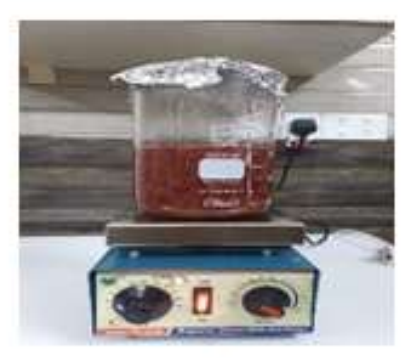

A

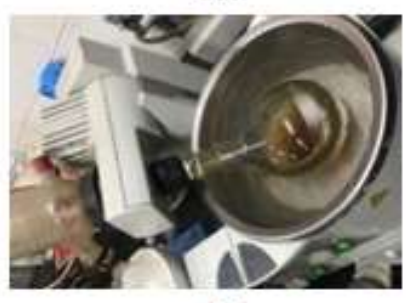

$\mathrm{C}$

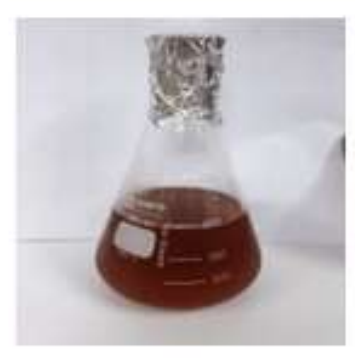

B

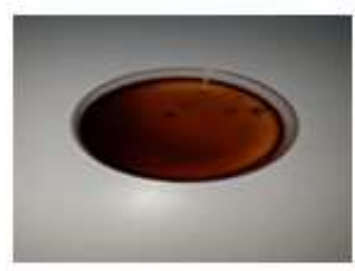

D

Figure 1: Extraction of RC isoflavones (A) RC soaked in Methanol, (B) RC after filter, (C) Methanol removal, (D) dried RC extract 


\section{Journal of Biotechnology Research Center}

Vol.15 No.2

Published Online: (December) 2021

\section{Preparation of NLCs}

One hundred $\mathrm{mg}$ of solid lipid (glyceryl monostearate) and liquid lipid (virgin coconut oil) range from $60 \%$ to $40 \%$, w/w were dissolved in 8.5 $\mathrm{ml}$ of Dichloromethane (DCM) were blended and melted at $40^{\circ} \mathrm{C}$ to form a uniform and clear lipid phase. (16) $6 \mathrm{mg}$ of isoflavones extract (17) subsequently added to the lipid phase and ensures heating temperature always maintained at $10^{\circ} \mathrm{C}$ above melting temperature of solid lipid. Meanwhile, the aqueous phase was prepared by blending $200 \mathrm{mg}$ of Tween 80 and $80 \mathrm{mg}$ of soy lecithin were prepared in $50 \mathrm{ml}$ D.W. Immediately, the aqueous mixture was added onto lipid mixture. The pre-emulsion was homogenized using Homogenizer at $11000 \mathrm{rpm}$ for 15 minute. The emulsions were ultrasonicated using probe sonicator for (5 to 20) min. durations at 40 amplitudes. To evaporate of DCM, the obtained nanoemulsion was stirred at $400 \mathrm{rpm}$ for $3 \mathrm{hrs}$. NLC was cooled in ice water bath to room temperature and stored at $4^{\circ} \mathrm{C}$. (16)

\section{Experimental design}

Two experiments were preformed, the first experiment for inducing menopause, included 20 adult female mice for two weeks and divided into two groups 10 mice in each one:

Group A: Control group has injected $0.1 \mathrm{ml} \mathrm{D.W}$ intraperitoneal (IP) daily.

Group B: This group has injected IP daily 160 $\mathrm{mg} / \mathrm{kg} \mathrm{B.W}$ of VCD. (18)

The second experiment was included 30 adult female mice have injected IP daily $160 \mathrm{mg} / \mathrm{kg}$ of VCD for inducing menopause for two weeks, then shaved at the last third of the back and divided into three groups (C, D and $\mathrm{E}), 10$ mice in each one, then treated with dermal sticker for six weeks:

Group C: The group was treated with dermal sticker saturated with $10 \mathrm{ug} / \mathrm{kg}$ B.W according to (19) of estradiol benzoate

Group D: Control group was treated with dermal sticker saturated with $0.1 \mathrm{ml}$ of virgin coconut oil.

Group E: The group was treated with dermal sticker saturated with $0.1 \mathrm{ml}$ of RCIE-NLCs.

\section{Results and Discussion}

The figure 2 showed concentrations of genistein, glycitein and malonate in RCIE by HPLC technique were $(2.7,6.6$ and 1.04$) \mathrm{mg} / \mathrm{g}$ respectively, in retention time $(5.196,7.023$ and 6.133) respectively. Figure 3 shows concentration of standards.

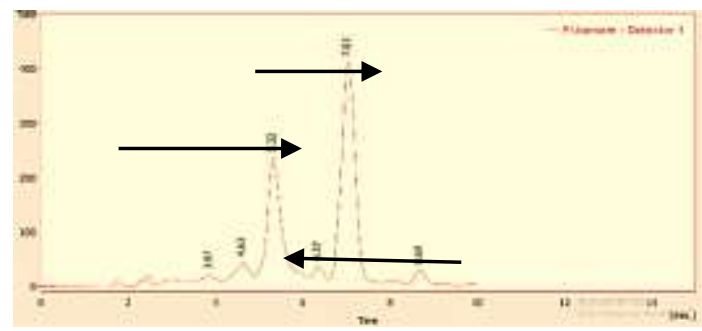

Figure 2: chromatographia HPLC of RCIE, A: Glycitein, B: Genistein, C: Malonate. 


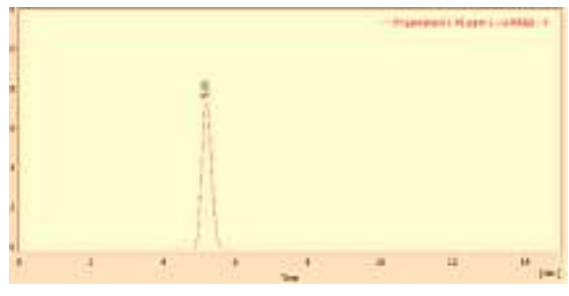

A

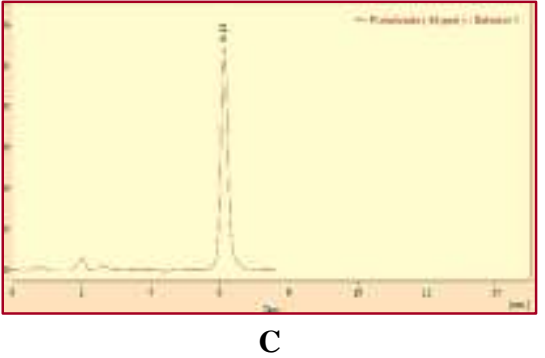

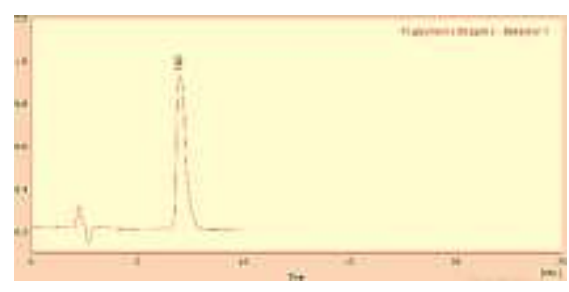

B

Figure 3: chromatographic HPLC of standards: A: Genistein, B: Glycitein, C: Malonate respectively.

\section{Characterization of NLC Formulation}

Figure 4 shows RCIE-NLCs with milky white solution, the proportions used in the preparation of
RCIE-NLCs were increased volume of aqueous phase, increase in drug content of particles and high concentration of surfactant.

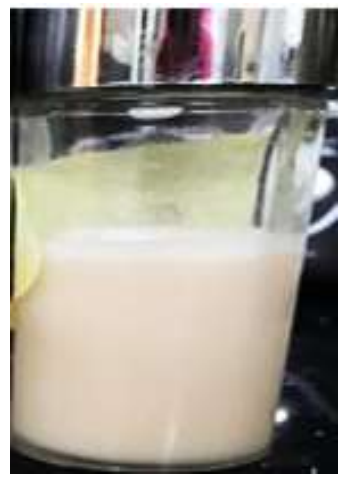

Figure 4: Nanostructured lipid carrier loaded with red clover extract

\section{Atomic force microscopy (AFM)}

Figure 5, A and B shows images at two and three dimensions of producing sample RCIE-NLCs. From Figure can note that the shape of particles was a mix between spherical and cylindrical. The grain size distribution of surface was about from (18 to 62) $\mathrm{nm}$ at average $38.78 \mathrm{~nm}$, Figure 5, C shows the histogram of grain size distribution on the surface. 


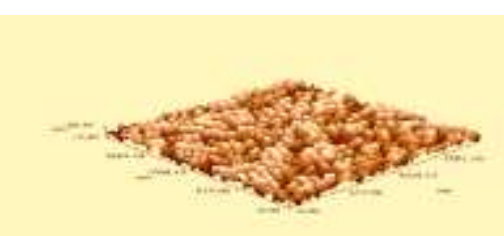

A

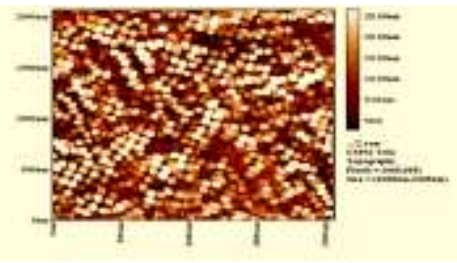

B

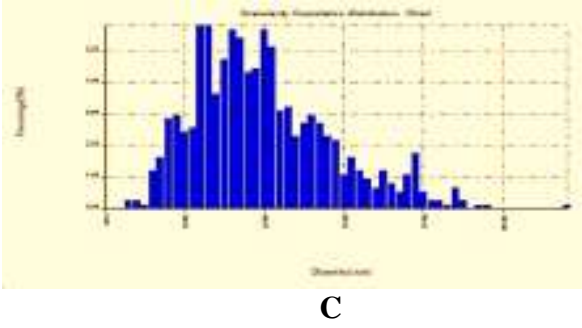

Figure 5: Images of (AFM) for RCIE-NLCs (A) two dimensions, (B) three dimensions, (C) histogram of the distribution of grain size

\section{Transmission electron microscopy (TEM)}

Figure 6, shows the image of TEM obtained from RCIE-NLCs. It can be shown the shape of particles was mostly spherical and few cylindrical with average diameter (53-10) $\mathrm{nm}$ and maximum distribution 40. Also the figures notice that the prepared RCIE-NLCs were highly dispersed and this indicates the quality of the prepared nanomaterial.

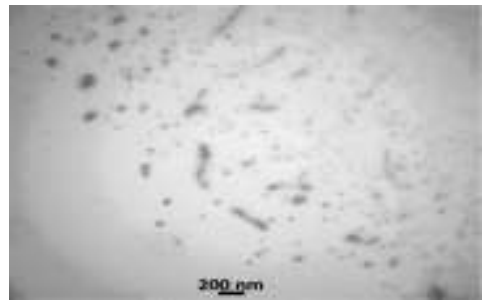

Figure 6: Transmission electron microscopy image of RCIE-NLCs formulation, with X34000.

\section{Zeta potential (ZP) determination}

Zeta potential of the formulation was determined to study the stability behavior of the formulation in vitro and in vivo which was found to be -41.1 may as show in Figure 7. It confirmed the stability of the colloidal system which is high enough to keep the particles aside and prevent the aggregates formation (20). Stepping up stability with higher surfactant levels. In general, ZP values larger than $\pm 30 \mathrm{mV}$ were good indications of static dispersion system stability. (21) 


\section{Encapsulation Efficiency (EE)}

The Concentration of the loaded RC extract in the NLC was calculated according to the following equation. $\mathrm{EE}(\%)=($ Total concentration of drug content- free drug / Total drug concentration of content) $\times 100$

The current study showed that concentration of genistein, glycitein and malonate were $(1.4,2.8$ and $0.8) \mathrm{mg} / \mathrm{g}$ respectively, in the RCIE-NLCs, when 6 $\mathrm{mg}$ of RC extract was used to load the NLC, approximately $1 \mathrm{mg}$ of free RC extract was detected in an aqueous RCIE-NLCs dispersion, suggesting that $5 \mathrm{mg}(83.3 \%$,) of RC extract was successfully encapsulated into the NLCs. Due to their better trapping effectiveness and greater formulation stability, NLCs were selected over the SLNs. In comparison with the solid lipids alone, liquid lipids in the formulation may transport longer drugs. Increased liquid lipid content might improve the EE of the formulation. (22). The proportion of oil phase to water phase exhibited a significant influence on the EE of NLC, which resulted in an increase in the EE of NLC .This might be because the particles were less aggregated in a wider area. Increased surfactant concentration also led to an increase of EE. Smaller surfactant concentrations and greater lipid concentrations will produce increased viscosity of formulation, leading to increased viscosity sensitivity to a shear force that prevents the production of nanodroplets and less drug volumes, and will ultimately lead to a decline in the EE lipid matrix. (23)

\section{Effect of VCD, EB, VCNO and RCIE-NLCs on Estrogen Levels}

Menopause is marked by hormonal changes from the reproductive to the non-reproductive stage of life. Table (1) shows the effect of VCD which caused a decreased in estrogen level compared with group control, and shows highly significant increase in ES levels in group EB compared to VCD group. Group VCNO had non-significant decrease in ES level compared with group EB. While group RCIE-NLCs had significant increase in ES level compared with group VCD. The VCD mouse model of menopause has been required repeated daily intraperitoneal injections of VCD causes loss of primordial and primary ovarian follicles, which generate estrogen hormone by acceleration of atresia, by alters the expression and distribution of the Bccl-2 family of proteins which regulate apoptosis (24) Decreasing the ovarian mRNAs, proteins and/or enzyme activity of estradiol generation and the sex steroid hormones precursor and VCD depleted all primordial follicles by 14 days of the end of daily dose through direct suppression of autophosphorylation by the survival receptors c-kit, situated on the oocyte plasma membrane. During this time frame, ovarian failure begins the cycle length increases, oestrogen levels vary to very low levels and therefore simulate human perimenopause. (25)

EB is an oestrogen medicine that is used in hormone treatment for menopause and low levels of estrogens in women, and is a drug-friendly ester for Estradiol, an endogenous natural hormone in the body. (26), Estradiol is the most powerful version and the main feminine sex hormone of all mammalian estrogen steroids. EB thus exerts the same downstream effects by attaching the estrogen receptor (ER) to different tissues, including in the breasts, cervics, ovaries, skin, prostate, bone, fat 
and brain, including ER $\alpha$ and ER $\beta$ subtypes. (27). Estradiol is relatively low in its own oral bioavailability $(2-10 \%)$. The metabolism of the first-pass gut and liver destroys the estradiol molecule fast before it is able to enter the systemic circulation and its oestrogenic effects (28). Phytoestrogens are structurally similar to natural estrols because they exhibit a phenolic ring with a radical carboxylate hydroxyl attached to carbon three, and give them the ability to engage in selectively high-intensity binding with oestrogen receptors. Phytoestrogens are still the most common types of phytoestrogens (29). Isoflavones are either estrogenic or anti-estrogenic depending on their concentration, gender and interaction with ERs on their unique target organ. (30). Compared to $17-\beta$-estradiol, about $1 / 1000$, Compared to $17-\beta$ estradiol, about 1/1000, isoflavones have an estrogenous potential lowhave an estrogenous potential low (11). Isoflavones may use other methods than ER to exercise their biological

\section{Effect of VCD, EB, Coconut oil and RCIE-NLCs on Lipids profile}

Hyperlipidaemia is a frequent symptom in women with menopause and is related with ovarian dysfunction. (35), VCD accelerate progression of metabolic syndrome. Table (2) shows effect of VCD which cause hyperlipidaemia in mice model for menopause, the statistical analysis showed highly significant increase in the TG, TC, LDL and VLDL compared with control group. VCD caused highly significant decreased in HDL level compared with control group, and non-significant decreased of EB effect on lipids profile compared with group VCD. Also group coconut oil had nonsignificant effect on lipids profile compared with group EB. While group RCIE-NLCs have positive significant effect on lipid profiles compared with groups VCD and EB. Increased fatty visceral tissue is a sign of metabolic syndrome. High levels of TG, TC, LDL-C, and VLDL-C are part of the metabolic syndrome. (36) The rise in plasma TG, TC, LDL-C, and VLDL-C has been seen following the discontinuation of menses, whereas HDL-C in women postmenopausal has been decreased. There are substantial changes also after menopause, which effects. , for example, may be used to control gene expression of estrogen-regulated products, by using tyrosine kinases and other peptide receptors on the plasma membrane of specific cells, isoflavones might bundle to the same ERs. The cell cycle modulation and antioxidant effects also comprise the putative modes of action of isoflavones. Intact nanoparticles larger than 100 nanometers do not penetrate the skin surface due to their diameters and hardness (31). As skin-rich epidermal lipids, lipid nanoparticles attached to the surface of the skin would permit lipid exchanges between the surface of the skin and nanoparticles. (32). NLs are capable of supplying drugs via follicles (33). Moreover, each follicle is linked to sebum-releating drums, which provide a lipid-enriched environment. This setting is useful for NL trapping. Some NLCs may speed up entry in follicles/sabaceous glands via glyceride lipids (34). And this is agreeing with our formulation RCIE-NLCs.

may cause cardiovascular conditions, such as an atherogenic lipid profile due to an increase of the overall level of cholesterol and LDL and decreased levels of HDL-C. (2)

As transdermal ES is not digested in the liver, passive skin diffusion enters the blood vessels, (37) The influence on the lipid profile of the first transit in the liver appears to be crucial. So this form of HRT is of no effect on the ES administration via the transdermal route, when compared to the oral method, and therefore has a lower influence on the lipid profile. (38) It delays and somewhat diminishes the impact of the transderm on the lipid profile. The transdermal route effects are thus only evident during extended treatment on lipids. (39) In this study, the transdermal administration of EB did not recorded a significant effect on the lipid profile, while in another study, researchers found that transdermal HRT had no effect on the hepatic enzyme. These results suggest that the initial liver passage's hepatic impact via the transdermal route is lower. (40) The method of ES delivery might further alter the quality of cholesterol molecules. Serum amyloid A (SAA) is an acute-phase liverproduced protein linked with the development and inflammation of atherosclerosis. (41). Coconut oil, 
made up of $92 \%$ saturated fatty acids, the majority of which (approximately 70\%) are fatty acids of the lower chain, known as medium chain fats (MCFAs). HDL in the VCNO group, MCFAs increased in no mean way (in triglyceride form), compared to group EB (MCFAs), and the ATP A1binding cassette transporter, preferentially upregulates the intestinal production of ApoAI (ABCA1). The interaction of apoA-I and ABCA1 facilitates an efflux of cell cholesterol to lipid-free apoA-I, facilitating the transport and synthesis of HDL particles in reverse cholesterol. (42). The present results of non- significantly change for TG, TC, LDL and VLDL compared with group EB may be because not all saturated fatty acids produce the same cholesterol-raising effects. Red clover-obtain isoflavones are beneficial for lipid profiles (43), particularly if they are in the form of nanoparticles. It has been demonstrated that genistein binds directly to ER $\beta$ and modulates endothelial cells, prompting nitric oxide production with activation of ER $\beta$, which in turn induces potentially significant vascular anti-inflammatory and antiatherogene effects. (44) Isoflavones lowers LDL-C and enhance hepatic LDL receptors via inhibition of $7 \alpha-$

\section{Conclusion}

Due to decreased oestrogen production, menopause can lead to different alterations in lipid metabolism. These modifications include an improved fat mass and lower fat-free mass which affects the basic metabolic rate. This study has been used by RCIE-NLCs to assess the effectiveness and safety of a new Nano Transdermal Protective Protocol for the control of lipid metabolism hydroxylase to reduce endogenous synthesis of cholesterol. (45). Isoflavone have many mechanisms, including prevention of cholesterol biosynthesis and esterification. The main lipoprotein of LDL particles is much less HepG2 release of apolipoprotein B (46), isoflavones enhance the abundance of sterol Regulatory Element Binding Protein (SREBP) and Sterol Regulatory Element (SRE) expression in HepG2 cells and, in fact, these increases lead to increased LDL-receptor surface expression. (47) Relevant observations include an elevation in HDL-C and a drop in TG levels in the menopausal mice model. The efficacy mechanism of isophlavones might be based on the phytoestrogenic characteristics of the red clover isoflavones, enhance the gene expression of apoprotein AI and result in higher in HDL hepatic composition and therefore in serum HDL levels. Isoflavones down control the quantity of mature SREBP-1, the downstream target gene of AMPK is a key transcription factor in the development of fat synthesis, which leads to lower expression of lipogenic genes such as FAS and a concomitant reduction of serum hepatic TGs. (48)

founded on a nanostructured formula of isoflavones. The results of this study revealed that administration of RCIE-NLCs for six weeks as transdermal treatment shows significantly decrease the serum LDL, TC, TG levels and increase serum HDL level, and shows an effective in compensating for estrogen deficiency resulting from loss of primordial and primary follicles in the ovary via impact of VCD.

Table (1): Comparison between control, VCD, EB, Coconut oil and RCIE-NLCs groups in ES level:

\begin{tabular}{|c|c|c|c|c|c|c|}
\hline \multirow{2}{*}{ Mean \pm SE } & \multicolumn{5}{|c|}{ Groups } \\
\cline { 2 - 6 } & Control & VCD & EB & VCNO & RCIE-NLCs & LSD \\
\hline ES(ng/ml) & & & & & 2.001 \\
& $33.154 \pm 2.735$ & $2.127 \pm 23.767$ & $36.444 \pm 3.371$ & $24.728 \pm 2.775$ & $30.008 \pm 2.809$ & $* *$ \\
& b & D & a & d & c \\
\hline
\end{tabular}




\section{Journal of Biotechnology Research Center}

Vol.15 No.2

Published Online: (December) 2021
P-ISSN: 1815-1140

E-ISSN: 2708-1370

Table (2): Comparison between control, VCD, EB, Coconut oil and RCIE-NLCs groups on Lipids profile:

\begin{tabular}{|c|c|c|c|c|c|}
\hline \multirow[t]{2}{*}{ Groups } & \multicolumn{5}{|c|}{ Mean \pm SE $(\mathrm{mg} / \mathrm{dl})$} \\
\hline & TG & TC & LDL & HDL & VLDL \\
\hline Control & $\begin{array}{c}54.20 \pm 5.40 \\
\mathrm{~A}\end{array}$ & $\begin{array}{c}80.00 \pm 2.92 \\
\mathrm{~A}\end{array}$ & $\begin{array}{c}50.36 \pm 1.28 \\
\mathrm{a}\end{array}$ & $\begin{array}{c}23.00 \pm 2.92 \\
a\end{array}$ & $\begin{array}{c}10.84 \pm 0.48 \\
\mathrm{~A}\end{array}$ \\
\hline VCD & $\begin{array}{c}79.40 \pm 4.78 \\
B\end{array}$ & $\begin{array}{c}101.94 \pm 6.97 \\
\text { b }\end{array}$ & $\begin{array}{c}66.88 \pm 2.17 \\
b\end{array}$ & $\begin{array}{c}18.80 \pm 1.64 \\
b\end{array}$ & $\begin{array}{c}16.62 \pm 0.22 \\
\text { B }\end{array}$ \\
\hline EB & $\begin{array}{c}76.25 \pm 3.29 \\
\text { B }\end{array}$ & $\begin{array}{c}97.80 \pm 3.98 \\
\text { b }\end{array}$ & $\begin{array}{c}61.97 \pm 1.59 \\
b\end{array}$ & $\begin{array}{c}17.19 \pm 2.518 \\
\text { b }\end{array}$ & $\begin{array}{c}15.84 \pm 0.29 \\
\text { B }\end{array}$ \\
\hline $\begin{array}{l}\text { Coconut } \\
\text { oil }\end{array}$ & $\begin{array}{c}75.53 \pm 3.33 \\
\text { B }\end{array}$ & $\begin{array}{c}97.22 \pm 4.39 \\
\text { b }\end{array}$ & $\begin{array}{c}65.99 \pm 1.52 \\
\text { B }\end{array}$ & $\begin{array}{c}19.36 \pm 1.45 \\
\text { B }\end{array}$ & $\begin{array}{c}15.96 \pm 0.39 \\
\text { B }\end{array}$ \\
\hline $\begin{array}{l}\text { RCIE- } \\
\text { NLCs }\end{array}$ & $\begin{array}{c}60.88 \pm 5.04 \\
D\end{array}$ & $\begin{array}{c}86.03 \pm 6.42 \\
d\end{array}$ & $\begin{array}{c}49.71 \pm 0.83 \\
\mathrm{Ac}\end{array}$ & $\begin{array}{c}22.99 \pm 3.15 \\
\text { a }\end{array}$ & $\begin{array}{c}12.16 \pm 0.50 \\
C\end{array}$ \\
\hline LSD value & $4.357 * *$ & $5.463 * *$ & $\mathbf{5 . 3 5 5} * *$ & $2.254 * *$ & $1.144 * *$ \\
\hline
\end{tabular}

cancer risk, Journal of the National Cancer Institute. (2003); 95(15): 1158-1164.

\section{References}

1. Landgren BM, Collins A, Csemiczky G, Burger H.G, Baksheev L, Robertson DM. Menopause transition:Annual changes in serum hormonal patterns over the menstrual cycle in women during a nine-year period prior to menopause. J. Clin. Endocrinol. Metab. (2004); 89: 2763-2769.

2. Seong HK , Hyun SK. Menopause-Associated Lipid Metabolic Disorders and Foods Beneficial for Postmenopausal Women. Nutrients. (2020); 12: 202.

3. Ebtekar F, Dalvand S, Gheshlagh RG. The prevalence of metabolic syndrome in postmenopausal women:A systematic review and meta-analysis in Iran. Diabetes Metab. Syndr. (2018); 12: 955-960.

4. Marta DA, Valentina EB, Michela V, Nicoletta Biglia. Current Evidence of the Oncological Benefit-Risk Profile of Hormone Replacement Therapy. Medicina. (2019); 55: 573.

5. Ivana, L, Ivana M, Savić G, Ana D. Classification and biological activity of phytoestrogens. (2017); 6(2): 96-106.

6. Horn-Ross PL, John EM, Canchola AJ, Stewart SL, Lee MM. Phytoestrogen intake and endometrial
7. Myers SP, Vigar V. Effects of a standardised extract of Trifolium pratense (Promensil) at a dosage of $80 \mathrm{mg}$ in the treatment of menopausal hot flushes: a systematic review and meta-analysis. Phytomedicine. (2017); 24: 141-147.

8. Luís Â, Domingues F, Pereira L. Effects of red clover on perimenopausal and postmenopausal women's blood lipid profile: A meta-analysis, Climacteric.(2018); 21(5): 446-453.

9. Ghazanfarpour M, Sadeghi R, Roudsari RL, et al. Red clover for treatment of hot flashes and menopausal symptoms: a systematic review and meta-analysis. J Obstet Gynaecol. (2016); 36: 301-311.

10. Ghazanfarpour M, Sadeghi R, Latifnejad RR. Effects of red clover on hot flash and circulating hormone concentrations in menopausal women: a systematic review and meta-analysis. Avicenna J Phytomedicine. (2015); 5: 498-511.

11. Setchell K. The history and basic science development of soy isoflavones. Menopause. (2017); 24(12): 1338-1350.

12. Manson JE, Chlebowski RT, Stefanick ML, Aragaki AK, Rossouw JE, Prentice, et all. Menopausal 
Vol.15 No.2

Published Online: (December) 2021
P-ISSN: 1815-1140

E-ISSN: 2708-1370
Hormone Therapy and Health Outcomes During the Intervention and Extended Post stopping Phases of the Women's Health Initiative Randomized Trials. JAMA. (2013); 310: 1353-1368.

13. Wang S, Dunlap TL, Howell CE, Mbachu OC, Rue EA, Phansalkar R, et all. Hop (Humulus lupulus L.) extract and 6-prenylnaringenin induce P450 1A1catalyzed estrogen 2-ydroxylation. Chem. Res. Toxicol.(2016); 29: $1142-1150$.

14. Purohit DK, Nandgude TD, Poddar SS. Nanolipid carriers for topical application: Current scenario. Asian J Pharm. (2016); 10: 1-9.

15. Sala M, Diab R, Elaissari A, Fessi H. Lipid nanocarriers as skin drug delivery systems: Properties, mechanisms of skin interactions and medical applications. International Journal of Pharmaceutics. (2018); 535(12):1-17.

16. Negi LM, Jaggi M, Talegaonkar S. Development of protocol for screening the formulation components and the assessment of common quality problems of nanostructured lipid carriers. International journal of pharmaceutics. (2014); 461(1): 403-410.

17. Kawakita S, Marotta F, Naito Y, Gumaste U, Jain S , Tsuchiya J , Minelli E. Effect of an isofl avonescontaining red clover preparation and alkaline supplementation on bone metabolism in ovariectomized rats.(2009); 4: 91-100.

18. Wright LE, Frye JB, Lukefahr AL, Marion SL, Hoyer PB , Besselsen DG, et al. 4-Vinylcyclohexene diepoxide (VCD) inhibits mammary epithelial differentiation and induces fibroadenoma formation in female Sprague Dawley rats. Reprod Toxicol. (2011); 32(1): 26-32.

19. Safety data sheet, Estradiol Benzoate. (EC). (2015); US OSHA HCS.

20. Korolev VV. Adsorption and magnetocaloric properties of some highly dispersed magnets, Dr.Sc. Diss., Ivanovo.(2014).

21. Wissing SA, M“uller RH. Solid lipid nanoparticles as carrier for sunscreens: in vitro release and in vivo skin penetration. Journal of Controlled Release. (2002); 81(3): 225-233.
22. Ghanbarzadeh $\mathrm{S}$, Hariri $\mathrm{R}$, Kouhsoltani $\mathrm{M}$, Shokri M, Javadzadeh Y, Hamishehkar H. Enhanced stability and dermal delivery of hydroquinone using solid lipid nanoparticles. Colloids and Surfaces B: Biointerfaces . (2015); 136: 1004-1010.

23. Sharma N, Madan $\mathrm{P}$, Lin S. Effect of process and formulation variables on the preparation of parenteral paclitaxel-loaded biodegradable polymeric nanoparticles: A co-surfactant study. Asian journal of pharmaceutical sciences. (2016); 11(3): 404-416.

24. Brooks HL, Pollow DP, Hoyer PB. The VCD Mouse Model of Menopause and Perimenopause for the Study of Sex Differences in Cardiovascular Disease and the Metabolic Syndrome. PHYSIOLOGY.n(2016); 31: 250-257.

25. Palacios S, Henderson VW, Siseles N, Tan D, Villaseca P. Age of menopause and impact of climacteric symptoms by geographical region. Climacteric. (2010); 13: 419-428.

26. Pinel G, Rambaud L, Cacciatore G. et al. Elimination kinetic of 17 beta-estradiol 3-benzoate and 17beta-nandrolone laureate ester metabolites in calves' urine. The Journal of steroid biochemistry and molecular biology . (2017); 110: 30-38.

27. Michael O, Ekkehard S. Estrogens and Antiestrogens I: Physiology and Mechanisms of Action of Estrogens and Antiestrogens. Springer Science \& Business Media. pp. 8. (2012).

28. Kenneth B, Finn H, Hans B. Oral bioavailability of $17 \beta$-estradiol and various ester prodrugs in the rat. International Journal of Pharmaceutics. (1991); 76, Isuues1-2: 177-182.

29. Bedani R, Rossi EA. Isoflavonas: bioquímica, fisiologia e implicações para a saúde. Bol. (2005); 23(2): 231-264.

30. Vitale DC, Piazza C, Melilli B, Drago F, Salomone S. Isoflavones: Estrogenic activity, biological effect and bioavailability. Eur. J. Drug Metab. Pharmacokinet. (2013); 38: 15-25.

31. Cevc G. Lipid vesicles and other colloids as drug carriers on the skin. Adv Drug Deliver.9(2004); 56: 675711. 
Vol.15 No.2

Published Online: (December) 2021
P-ISSN: 1815-1140

E-ISSN: 2708-1370
32. Müller RH, Petersen RD, Hommoss A, Pardeike J. Nanostructured lipid carriers (NLC) in cosmetic dermal products. Adv Drug Deliv Rev. (2007); 59: 522-530.

33. Chen H, Chang X, Du D, et al. Podophyllotoxinloaded solid lipid nanoparticles for epidermal targeting. J Control Release. (2006); 110: 296-306.

34. Sarabjot k, Ujjwal N, Ramandeep S, Satvinder S, Anita D. Nanostructure Lipid Carrier (NLC): the new generation of lipid nanoparticles. Asian Pac. J. Health Sci. (2015); 2(2): 76-93.

35. Xiaoxue X, Lina S, Patrick FA, Lingyan W, Lan L, Erwei L, et al. Danzhi Qing'e (DZQE) activates AMPK pathway and regulates lipid metabolism in a rat model of perimenopausal hyperlipidaemia. Exp Physiol. (2016); 101(11): 1406-1417.

36. Abolfazl M, Hamid F, Esmail M, Mahbobeh S, Robabeh A, Sima A. Prevalence of Metabolic Syndrome and Associations with Lipid Profiles in Iranian Men: A Population-Based Screening Program. World J Mens Health. (2018) Jan; 36(1): 50-56.

37. Daniel RC, Danyelle RA, Sílvio AF, Maria RT. Transdermal Estradiol and Lipid Profile: Effects on a Specific Group of Brazilian Postmenopausal Women. Arq Bras Cardiol . (2009); 93(6): 571-575.

38. Scarabin PY, Oger E, Plu BG. Differential association of oral and transdermal oestrogenreplacement therapy with venous thromboembolism risk. Lancet. (2003); 362: 428-432.

39. Mattsson LA, Samsioe G, and von SB, Uvebrandt M, Wilklund I. Transdermally administered oestradiol combined with oral medroxyprogesterone acetate: the effects on lipoprotein metabolism in postmenopausal women. Br J Obstetr Gynecol. (1993); 100(5): 450-453.

40. Kenemans P, Van Unnik GA, Mijatovic V, Van der Mooren MJ. Perspectives in hormone replacement therapy. Maturitas. (2001); 38(Suppl.1): 41-48.
41. Liang JS, Schreiber BM, Salmona M, et al. Amino terminal region of acute phase, but not constitutive, serum amyloid A (apoSAA) specifi cally binds and transports cholesterol into aortic smooth muscle and HepG2 cells. J Lipid Res. (1996); 37: 2109-2116.

42. Wang S, Smith JD. ABCA1 and nascent HDL biogenesis. Biofactors. (2014); 40(6):547-554.

43. Milan MT, Jelena D, Sanja M, Tihomir M , Bratislava TR. Influence of red clover-derived isoflavones on serum lipid profile in postmenopausal womenjog. J. Obstet. Gynaecol. Res. (2009) Des; 35(6): 1091-1095.

44. Luis AH, Peter AC, Nancy M, Susana R, Glenda $\mathrm{SM}$. The effect of red clover isoflavones on menopausal symptoms, lipids and vaginal cytology in menopausal women: A randomized, double-blind, placebo-controlled study. Gynecological Endocrinology. (2005) Nov; 21(5): 257-264

45. Wang MF, Yamamoto S, Chung HM, Chung SY, Miyatani S, Mori M, et al. Antihypercholesterolemic effect of undigested fraction of soybean protein in young female volunteers. J Nutr Sci Vitaminol . (1995); 41:187195.

46. Borradaile NM, de Dreu LE, Wilcox LJ, Edwards JY, Huff MW. Phytoestrogens, genistein and daidzein, decrease apolipoprotein B secretion from HepG2 cells through multiple mechanisms. Biochem J. (2002); 366: 531-539.

47. Mullen E, Brown RM, Osborne TF, Shay NF. Soy isoflavones affect sterol regulatory element binding proteins (SREBPs) and SREBPregulated genes in HepG2 cells. J Nutr . (2004); 134: 2942-2947.

48. Espenshade PJ. SREBPs: sterol-regulated transcription factors. J Cell Sci1. (2006); 19: 973-976. 
Vol.15 No.2

\section{Journal of Biotechnology Research Center}

$$
\begin{aligned}
& \text { إنتاج وتوصيف جزيئات الاهن النانوية المحملة بايزوفلافونات البرسيم الاحمروتأثيرها على مستوى الدهون } \\
& \text { في مرحلة سن اليأس }
\end{aligned}
$$

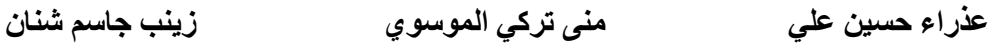

Corresponding author: athraahussain2002@gmail.com

الجسيمات النانوية الصالحة للاكل المثتقة من النبات (PDNPs) عبارة عن حويصلات غثائية بحجم النانو تطلقها النباتات الصالحة للأكل.

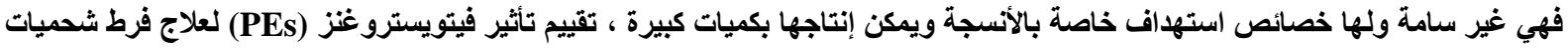

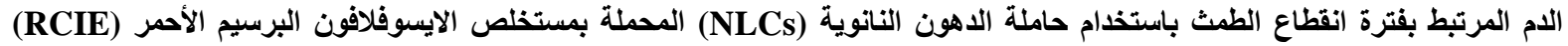

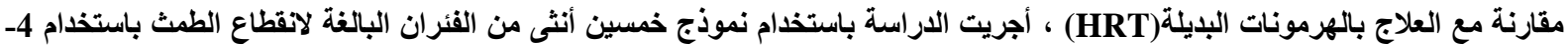

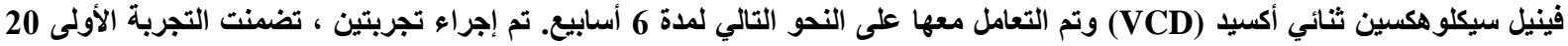

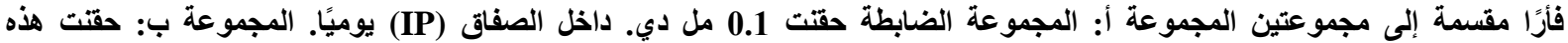

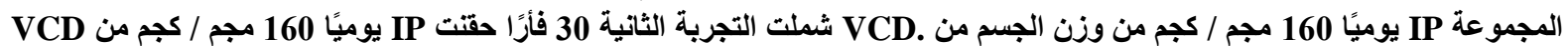

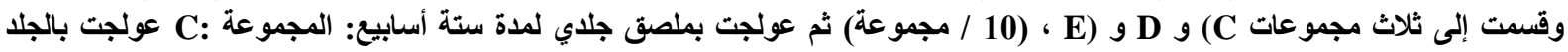

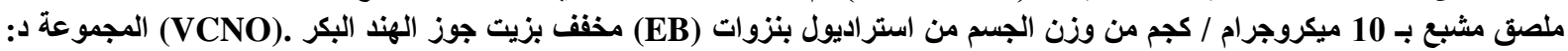

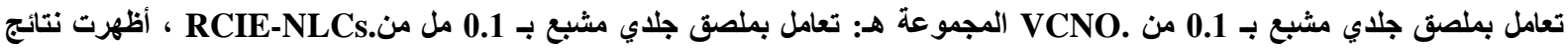

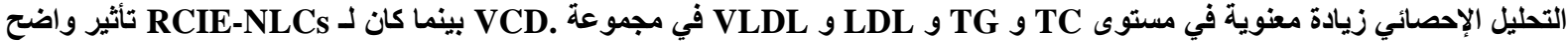

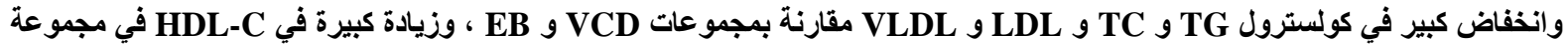

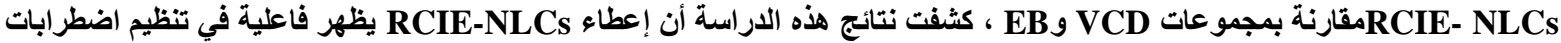

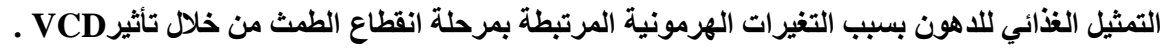

الكلمات المفتاحية: البرسيم الأحمر ، سن الئس ، NLCs فرط شحميات الام ، بنزوات الاستروجين. 